\title{
DESKRIPSI SARANA PEMBELAJARAN PRAKTIKUM UNTUK MENCAPAI TINGKAT KOMPETENSI ENGINE TUNE-UP
}

\author{
Asep Y. Jaenudin ${ }^{1}$, Inu H. Kusumah ${ }^{2}$, Tatang Permana ${ }^{3}$ \\ Universitas Pendidikan Indonesia \\ Jl. Dr. Setiabudhi No. 229 Bandung 40154 \\ ayogajaenudin06@gmail.com
}

\begin{abstract}
ABSTRAK
Hasil observasi yang dilakukan pada SMK Swasta di Majalengka, menunjukkan masih kurangnya sarana praktikum di workshop Otomotif. Tujuan penelitian untuk mengetahui sarana pembelajaran praktikum di workshop Otomotif sesuai kriteria Standar Nasional Pendidikan. Metode yang digunakan dalam penelitian ini adalah deskriptif dengan pendekatan kuantitatif. Subjek penelitian ini yaitu guru produktif dan kepala bengkel. Objek penelitiannya yaitu tentang sarana pembelajaran praktikum otomotif di workshop otomotif. Teknik pengumpulan data dalam penelitian ini menggunakan teknik observasi dan dokumentasi. Hasil penelitian diperoleh persentase kelayakan sarana pembelajaran praktikum engine tune-up adalah sangat lengkap/sangat layak berdasarkan standar dari BSNP. Hasil observasi dan dokumentasi yang disesuaikan terhadap instrumen verifikasi SMK penyelenggara ujian praktikum kejuruan dari BSNP. Kesimpulan penelitian ini yaitu bahwa sarana pembelajaran praktikum yang terdapat di workshop otomotif SMK PGRI Jatiwangi dan SMKN 1 Palasah sangat lengkap/sangat layak memenuhi standar uji kompetensi.
\end{abstract}

Kata kunci: sarana praktikum, otomotif, workshop, tune-up

\section{PENDAHULUAN}

Pembangunan bidang pendidikan di Indonesia diarahkan kepada pengembangan sumber daya manusia yang bermutu tinggi, guna memenuhi kebutuhan dan menghadapi tantangan kehidupan di masa depan, melalui pendidikan, sumber daya manusia yang bersifat pontesi diaktualisasikan menjadi kompetensi yang optimal. Pendidikan nasional ditujukan untuk mewujudkan cita-cita kemerdekaan bangsa Indonesia khususnya dalam upaya mencerdaskan kehidupan bangsa sehingga akan menjadi bangsa yang beradab dan dapat bersaing di dunia Internasional.

Hal tersebut diimplementasikan dalam Undang-Undang (UU) Nomor 20 Tahun 2003 pasal 3 tentang Sistem Pendidikan Nasional menyatakan bahwa: Pendidikan nasional berfungsi mengembangkan kemampuan dan membentuk watak serta peradaban bangsa yang bermartabat dalam rangka mencerdaskan kehidupan bangsa, bertujuan untuk berkembangnya potensi peserta didik agar menjadi manusia yang beriman dan bertaqwa kepada Tuhan Yang Maha Esa, berakhlak mulia, sehat, berilmu, cakap, kreatif, mandiri dan menjadi warga negara yang demokratis serta bertanggung jawab.

\footnotetext{
${ }^{1}$ Mahasiswa Departemen Pendidikan Teknik Mesin FPTK, UPI

2 Dosen Departemen Pendidikan Teknik Mesin FPTK, UPI

${ }^{3}$ Dosen Departemen Pendidikan Teknik Mesin FPTK, UPI
} 
Pendidikan merupakan suatu sistem yang terdiri dari beberapa komponen. Salah satunya adalah sarana dan perasarana yang dibutukan dalam proses belajar dan mengajar di sekolah. Berbicara sarana dan prasarana di dalam lingkungan pendidikan merupakan aspek yang menarik untuk di ulas, apalagi dalam kegiatan proses belajar dan pembelajaran di sekolah yang berhubungan dengan penggunaan sarana dan prasarana (Arifin dan Barnawi, 2012).

Sekolah Menengah Kejuruan (SMK) tidak bisa di pisahkan dengan peranan sarana pembelajaran. SMK dengan adanya aspek keterampilan yang didapat melalui pembelajaran praktikum dengan alokasi waktu yang diberikan untuk melakukan pembelajaran praktikum lebih besar dibandingkan alokasi waktu pembelajaran teori. Artinya bahwa lulusan SMK ini untuk siap bekerja dan mendalami bidang kejuruan tertentu.

SMK sekarang ini sedang dikembangkang oleh pemerintah, tentu sangat diharapkan untuk menghasilkan lulusan SMK yang berprestasi, siap pakai, dan mampu bersaing di dunia Industri. Peningkatan prestasi siswa khususnya lulusan SMK yang diharapkan, salah satu faktor ketercapainya lulusan yang diharapkan adalah lengkapnya sarana pembelajaraan yang dimiliki sekolah tersebut (Santoso, Suhardjono, Hariyan, 2012). Peraturan Menteri Pendidikan Nasional Republik Indonesia No. 40 Tahun 2008 tentang Standar Sarana dan Prasarana Untuk Sekolah Menengah Kejuruan (SMK) dan Madrasyah Aliyah kejuruan (MAK) pada pasal 4 dijelaskan bahwa: Penyelenggaraan sekolah menengah kejuruan/madrasah aliyah kejuruan (SMK/MAK) wajib menerapkan standar sarana dan prasarana sekolah menengah kejuruan/madrasah aliyah kejuruan (SMK/MAK) sebagaimana diatur dalam Peraturan Menteri ini, selambat-lambatnya 5 (lima) tahun setelah Peraturan Menteri ini ditetapkan. Sekolah khususnya SMK dan MAK harus memenuhi standar sarana dan prasarana yang dijelaskan di atas agar tujuan pendidikan bisa tercapai dan hasil dari lulusan SMK ini dapat berkualitas.

Sarana pembelajaran praktikum merupakan salah satu faktor penunjang untuk mencapai hasil belajar yang optimal. Dalam pengajaran engine tune-up sarana pembelajaran yang memadai sangat penting untuk meningkatkan dan mengembangkan kualitas proses belajar mengajar. Kelengkapan sarana pembelajaran praktik besar sekali manfaatnya bagi guru dan siswa, sehingga pembelajaran dapat berjalan lancar serta tujuan pembelajaran dapat tercapai dengan baik. Namun sebaliknya sarana pembelajaran praktik yang tidak lengkap atau tidak sesuai dengan standar nasional pendidikan akan menyulitkan guru dan siswa. Pembelajaran tidak dapat disampaikan pada siswa dan tujuan pembelajaran tidak dapat tercapai (Manaf, 2013). 
Pencapian tujuan pendidikan khususnya SMK sangat tergantung dari sarana pembelajaran praktik. Tujuan pendidikan akan berjalan lancar, apabila di dukung dengan sarana pembelajaran yang cukup dan memadai baik dari kualitas maupun kuantitas. Berkaitan dengan sarana pembelajaran peneliti akan mengkaji kelengkapan sarana pembelajaran praktik SMK Negeri dan Swasta di Kabupaten Majalengka. Berdasarkan observasi awal yang telah dilakukan di PGRI Jatiwangi, diperoleh informasi bahwasanya sekolah ini masih kurang memadai. Hal ini terlihat jelas ketika pengamatan pertama ke workshop Otomotif terutama pada area kerja mesin otomotif yang kurang sesuai dengan standar. Hasil pengamatan pertama yaitu area kerja mesin otomotif dengan jumlah rata-rata siswa 40 orang, luas $50 \mathrm{~m}^{2}$, lebar $5 \mathrm{~m}$, panjang $10 \mathrm{~m}$.

Mengenai sarana pembelajaran tersebut, yang perlu di perhatikan karena dampaknya pada kemampuan kompetensi siswa yang di tuntut kompeten. Idealnya kompetensi lulusan SMK bisa terserap oleh dunia usaha dan dunia industri. Begitu juga dengan sarana pembelajaraan yang di adakan oleh sekolah harus sesuai dengan standar kompetensi lulusan SMK. Peran sarana pembelajaraan pendidikan dalam proses pembelajaran mempunyai peranan yang penting. Khususnya pada pembelajaran praktikum di Sekolah Menengah Kejuruan, mengingat praktik merupakan salah satu hal yang sangat penting dalam pembelajaran di SMK. Sarana pembelajaraan yang dimiliki oleh SMK yang digunakan untuk pembelajaran praktikum siswa akan mempengaruhi kualitas hasil dari proses pembelajaran (Amirin, 2011).

\section{METODE PENELITIAN}

Metode yang digunakan peneliti dalam penelitian ini adalah metode deskriptif dengan pendekatan kuantitatif. Penggunaan pendekatan ini mengacu pada tujuan penelitian, yakni untuk memperoleh gambaran nyata tetang sarana pembelajaran praktikum di SMK PGRI Jatiwangi dan SMKN 1 Palasah. Data yang diperoleh diharapkan mampu untuk menggambarkan keadaan nyata yang terjadi dilapangan, dengan paparan seluasluasnya. Penelitian deskriptif adalah suatu metode dalam meneliti status sekelompok manusia, suatu objek, suatu set kondisi, suatu sistem pemikiran ataupun suatu kelas peristiwa pada masa sekarang.

Subjek penelitian dalam penelitian ini yaitu guru produktif khususnya kepala bengkel, dan objek penelitiannya yaitu tentang sarana pembelajaran praktikum otomotif di workshop otomotif SMK PGRI Jatiwangi dan SMKN 1 Palasah. Teknik pengumpulan data digunakan teknik observasi dan dokumentasi. Instrumen penelitian yang digunakan yaitu 
lembar observasi dan panduan dokumentasi. Data yang digunakan pada penelitian ini adalah hasil observasi dan dokumentasi. Pengolahan data hasil wawancara dan observasi disesuaikan dengan data hasil penelitian pada standar sarana dan prasarana yang seharusnya. Kondisi sarana pembelajaran praktikum workshop SMK PGRI Jatiwangi dan SMKN 1 Palasah yang ada sekarang sesuai dengan standar atau belum memenuhi standar yang berlaku. Teknik analisis data yang digunakan statistik deskriptif. Teknik analisis data menggunakan persentase, dengan kreteria pencapaian, sebagai berikut: 0\%-20\% sangat tidak lengkap/sangat tidak layak, 21\%-40\% tidak lengkap/tidak layak, 41\%-60\% kurang lengkap/kurang layak, 61\%-80\% lengkap/layak, dan 81\%-100\% sangat lengkap/sangat layak.

\section{HASIL PENELITIAN}

Hasil penelitian melalui deskripsi data yang telah diperoleh, meliputi aspek-aspek: sarana di area ruang kerja mesin otomotif, area ruang penyimpanan dan instruktur, persyaratan utama uji kompetensi, persyaratana pendukung uji kompetensi, persyaratan penguji internal, persyaratan penguji eksternal, dan persyaratan ruang/tempat uji kompetensi.

Hasil observasi dan dokumentasi, pencapaian standar sarana pada area kerja mesin otomotif di workshop otomotif SMK PGRI Jatiwangi mencapai 85,7\% dan di workshop otomotif SMKN 1 Palasah mencapai $85,7 \%$. Prentasi tersebut artinya tingkat ketercapian untuk standar sarana di area kerja mesin otomotif workshop otomotif dinyatakan sangat layak/sangat lengkap yang disesuaikan terhadap Instrument Verifikasi SMK Penyelenggara Ujian Praktikum Kejuruan dari BSNP.

Hasil observasi dan dokumentasi, pencapaian standar sarana pada area ruang penyimpanan dan instruktur di workshop otomotif SMK PGRI Jatiwangi mencapai 87,5\% dan di workshop otomotif SMKN 1 Palasah mencapai 100\%. Angka tersebut menunjukkan tingkat ketercapaian untuk standar sarana di area kerja mesin otomotif workshop otomotif dinyatakan sangat layak/sangat lengkap yang disesuaikan terhadap Instrument Verifikasi SMK Penyelenggara Ujian Praktikum Kejuruan dari BSNP.

Hasil observasi dan dokumentasi, pencapaian standar peralatan utama uji kompetensi di workshop otomotif SMK PGRI Jatiwangi mencapai 90,1\% dan di workshop otomotif SMKN 1 Palasah mencapai 93,2\%. Hasil observasi dan dokumentasi, pencapaian standar peralatan pendukung uji kompetensi di workshop otomotif SMK PGRI Jatiwangi mencapai 90,8\% dan di workshop otomotif SMKN 1 Palasah mencapai 91,5\%. Hasil ini diperoleh 
dari indikator ketercapaian sarana pembelajaran praktikum dalam penelitian ini antara lain spesifikasi alat, jumlah alat, kondisi alat. Secara rinci hasil itu didapat dari pengolahan data SMK PGRI Jatiwangi mendapat persentase untuk tingkat pencapaian standar persyaratan peralatan pendukung untuk uji kompetensi terhadap kualitas spesifikasi alat pencapaian $88,2 \%$. Persentase tingkat ketercapaian standar persyaratan peralatan pendukung untuk uji kompetensi terhadap kualitas jumlah alat mencapai 92,1\%. Kemudian persentase tingkat ketercapaian standar persyaratan pendukung untuk uji kompetensi terhadap kualitas kondisi alat mencapai $92,1 \%$ di SMKN 1 Palasah. Persentase untuk tingkat pencapaian standar persyaratan peralatan pendukung untuk uji kompetensi terhadap kualitas spesifikasi alat pencapaian 90,1\%. Persentase tingkat ketercapaian standar persyaratan peralatan pendukung untuk uji kompetensi terhadap kualitas jumlah alat mencapai 90,1\%. Persentase tingkat ketercapaian standar persyaratan pendukung untuk uji kompetensi terhadap kualitas kondisi alat mencapai $94,1 \%$.

Hasil observasi dan dokumentasi, pencapaian standar kondisi tempat/ruang uji kompetensi di workshop otomotif SMK PGRI Jatiwangi dan di workshop otomotif SMKN 1 Palasah. Standar persyaratan tempa/ruang pada SMK PGRI Jatiwangi untuk uji kompetensi pada persyaratan tempa/ruang sudah sepenuhnya sesuai standar. Perbandingan skala 1 sampai 3 yaitu tidak layak, layak, dan sangat layak. Persentase untuk tingkat pencapaian standar persyaratan tempat/ruang untuk uji kompetensi mencapai 90,4\%. SMKN 1 Palasah menunjukkan bahwa standar persyaratan tempa/ruang untuk uji kompetensi pada persyaratan tempa/ruang sudah sepenuhnya sesuai standar. Perbandingan skala 1 sampai 3 yaitu tidak layak, layak, dan sangat layak. Persentase untuk tingkat pencapaian standar persyaratan tempat/ruang untuk uji kompetensi mencapai 95,2\%.

Hasil observasi dan dokumentasi, pencapaian standar peralatan pendukung uji kompetensi di workshop otomotif SMK PGRI Jatiwangi dan di workshop otomotif SMKN 1 Palasah, menunjukkan bahwa standar persyaratan penguji internal untuk uji kompetensi. Persyaratan penguji internal sudah sepenuhnya sesuai standar, dengan perbandingan skala 1 sampai 3 yaitu tidak layak, layak, dan sangat layak. Persentase untuk SMK PGRI Jatiwangi tingkat pencapaian standar persyaratan penguji internal untuk uji kompetensi mencapai 91,6\%, untuk SMKN 1 Palasah mencapai 83,3\%, dan hasil untuk penguji eksternal pada tiap-tiap sekolah mencapai persentase $100 \%$. 


\section{PEMBAHASAN}

Lengkap tidaknya perlengkapan belajar baik yang dimiliki siswa maupun yang dimiliki sekolah menimbulkan hasil tertentu terhadap hasil belajar siswa. Kekurangan peralatan dapat membawa akibat negatif antara lain siswa tidak bisa belajar secara baik sehingga sulit diharapkan mencapai prestasi tinggi. Kondisi sarana pada area kerja mesin otomotif bisa dikatakan sangat layak/sangat lengkap dan bisa menimbulkan hasil yang positif terhadap hasil belajar siswa.

Lengkap tidaknya perlengkapan belajar baik yang dimiliki siswa maupun yang dimiliki sekolah menimbulkan hasil tertentu terhadap hasil belajar siswa. Kekurangan peralatan dapat membawa akibat negatif atara lain siswa tidak bisa belajar secara baik sehingga sulit diharapkan mencapai prestasi tinggi. Hasil observasi dan dokumentasi menunjukkan bahwa kondisi sarana pada area ruang penyimpanan dan instruktur bisa dikatakan sangat layak/sangat lengkap dan bisa menimbulkan hasil yang positif terhadap hasil belajar siswa (Ikhsan dan Anisykurlillah, 2010).

Secara keseluruhan hasil dari observasi dan dokumentasi dijelaskan bahwa sarana pada area kerja mesin otomotif, area ruangan dan instruktur dinyatakan sangat layak/sangat lengkap. Untuk dilakukannya proses belajar mengajar dan mendukung meningkatnya proses belajar mengajar seperti yang dikemukakan oleh pakar pendidikan. Hasil ini diperoleh dari indikator-indikator ketercapaian sarana pembelajaran praktikum dalam penelitian ini antara lain spesifikasi alat, jumlah alat, kondisi alat. Data SMK PGRI Jatiwangi menunjukkan persentase pencapaian standar persyaratan peralatan utama untuk uji kompetensi terhadap kualitas spesifikasi alat mencapai 88,8\%. Persentase tingkat ketercapaian standar persyaratan peralatan utama untuk uji kompetensi terhadap kualitas jumlah alat mencapai 92,5\%. Persentase tingkat ketercapaian standar persyaratan utama untuk uji kompetensi terhadap kualitas kondisi alat mencapai 88,8\%. Data SMKN 1 Palasah menunjukkan persentase pencapaian standar persyaratan peralatan utama untuk uji kompetensi terhadap kualitas spesifikasi alat mencapai 90,7\%. Persentase tingkat ketercapaian standar persyaratan peralatan utama untuk uji kompetensi terhadap kualitas jumlah alat mencapai 90,7\%. Persentase tingkat ketercapaian standar persyaratan utama untuk uji kompetensi terhadap kualitas kondisi alat mencapai 98,1\%. Artinya untuk ketercapaian standar peralatan utama uji kompetensi di workshop otomotif dinyatakan sangat layak/sangat lengkap dengan mendapat skor 2,70 untuk SMK PGRI Jatiwangi dan skor 2,79 untuk SMKN 1 Palasah. 
Ketercapaian standar peralatan pendukung uji kompetensi di workshop otomotif dinyatakan sangat layak/sangat lengkap dengan mendapat skor 2,72 untuk SMK PGRI Jatiwangi dan skor 2,76 untuk SMKN 1 Palasah, yang disesuaikan terhadap instrument verifikasi SMK penyelenggara ujian praktikum kejuruan dari BSNP. Ketercapaian standar peralatan pendukung uji kompetensi di workshop otomotif dinyatakan sangat layak/sangat lengkap dengan mendapat skor 2,71 untuk SMK PGRI Jatiwangi dan skor 2,85 untuk SMKN 1 Palasah, yang disesuaikan terhadap instrument verifikasi SMK penyelenggara ujian praktikum kejuruan dari BSNP. Ketercapaian standar penguji internal uji kompetensi dan penguji eksternal uji kompetensi di workshop otomotif dinyatakan sangat layak/sangat lengkap, yang disesuaikan terhadap instrument verifikasi SMK penyelenggara ujian praktikum kejuruan dari BSNP (Ibrahim, 2004).

\section{KESIMPULAN}

Kesimpulan dari penelitian nini, sebagai berikut: sarana pembelajaran praktikum engine tun-up menunjukkan sangat layak/sangat lengkap $(85,7 \%)$ untuk kedua SMK. Sarana pembelajaran praktikum yang terdapat di workshop otomotif SMK PGRI Jatiwangi dan SMKN 1 Palasah sangat layak/sangat lengkap untuk dijadikan tempat pelaksanaan praktikum.

\section{REFERENSI}

Manaf, A. (2013). Manajemen Sarana dan Prasarana Pendidikan pada Madrasah Sekolah. Jurnal Sarana dan Prasarana Pendidikan. Diakses dari http://www.slideshare.net/manafmada/jurnal-sarana-dan-prasarana-pendidikan.

Arifin, M. dan Barnawi. (2012). Manajemen Sarana dan Prasarana Sekolah. Jakarta: ArRuzz Media.

Ibrahim, B. (2004). Manajemen Perlengkapan Sekolah. Jakarta: PT. Bumikarsa.

Amirin, M.T. (2011). Pengertian sarana dan prasarana pendidikan. Jakarta: PT. Grafindo Persada.

Santoso, J., Suhardjono, Hariyan, S. (2012). Evaluasi Skala Pelayanan Prasarana Pendidikan Sekolah Menengah Kejuruan Di Kota Batu. Jurnal Rekayasa Sipil 6 (2) hal.156-167.

Ikhsan, S dan Anisykurlillah, I. (2010). Penerapan Manajemen Berbasis Sekolah SMK Negeri dan SMK Swasta Se-Karasidenan Semarang. Jurnal Pendidikan Ekonomi Dinamika Pendidikan V(1) hal.1-19. 